\title{
Laser photoplethysmography in integrated evaluation of collateral circulation of lower extremities
}

\author{
Sergii V.Sander ${ }^{\mathrm{a}}$, Tatiana I. Kozlovska ${ }^{\mathrm{b}}$, Valentina B. Vassilenko ${ }^{\mathrm{c}}$, Volodymyr S. Pavlov ${ }^{\mathrm{b}}$, Andrii \\ Yu. Klapouschak ${ }^{\mathrm{b}}$, Piotr Kisała*d, Ryszard S. Romaniuk ${ }^{\mathrm{e}}$, Azhar Sagymbekova ${ }^{\mathrm{d}, \mathrm{f}}$ \\ ${ }^{a}$ Vinnytsia National Medical University, Department of General Surgery, 21018 Ukraine, Vinnytsia, \\ Pirogova 56; 'binnytsia National Technical University, 95 Khmelnitske Sh., Vinnitsa 21021, \\ Ukraine; ' Universidade Nova de Lisboa, Faculdade de Ciências e Tecnologia, \\ 2829-516 Caparica, Portugal; ${ }^{\mathrm{d}}$ Lublin University of Technology, 38D Nadbystrzycka Street, 20-618 \\ Lublin, Poland; ${ }^{\mathrm{e} W a r s a w}$ University of Technology, Faculty of Electronics and Information \\ Technology, Institute of Electronic Systems; ${ }^{\mathrm{f}}$ Kazakh National Research Technical University after \\ K. I. Satpaev, 22, Satpaev Street, 050013 Almaty, Kazakhstan
}

\begin{abstract}
The paper evaluated the diagnostic value of laser photoplethysmography when examining patients with chronic lower limb ischemia. A statistical analysis of the research results was made, and diagrams of relationship between the degrees of ischemia and blood flow are presented.
\end{abstract}

Keywords: occlusive disease of lower extremity arteries, collateral circulation, survey laser photoplethysmography.

\section{INTRODUCTION}

Non-invasive diagnostic methods with optical registration and transformation of biomedical information extensive have been extensively developed for the last few years ${ }^{1-2}$. Laser photoplethysmography (LPPG) relates to one method of noninvasive optical diagnostics peripheral circulation. Method can improve the reliability of the control and peripheral circulation diagnostics and identify the effects on the autonomic nervous system, can serve for for evaluation of sympathetic innervation of the skin, can be used in the diagnostics of Raynaud's disease, early forms of atherosclerosis, thrombosis, etc.. This method can controll the depth of spinal anesthesia (simultaneous registration of vascular reaction taken from finger and toes). Besides, PPG has additional diagnostic and prognostic value in the study of many cardiovascular and neurological diseases, that are the most common causes of death and disability in young age ${ }^{3-5}$. Therefore, effective processing of photoplethysmographic information is very important. Laser Doppler flowmetry, capillaroscopy, scintigraphy, evaluation of infrared radiation are used for investigating the mikrohemodynamic indicators ${ }^{6-9}$. These methods reflect the state of circulatory limbs' compensatory mechanisms, that gives information about the development of collateral circulation indirectly. Although, their results do not allow to distinguish changes on the basis of micro- and macroangiopathy. Thus, the estimation the collateral circulation reserves has not been developed enough. The purpose is the evaluation of laser photoplethyzmohrafy's (LPPH) diagnostic value in examination of patients with chronic ischemia of lower extremities.

\section{MATERIALS AND METHODS}

There were examined 82 people in total. !8 pations have been diagnosed on the ischemia of the II degree, $8-$ on IIIA, 12 - on IIIB, and 15 - on IV. The key group consisted of 29 individuals without symptoms of obliterating diseases concerning lower limbs' arteries. Their age ranged from 18 to 82 years. It was conducted physical examination and LPPH. The latter has allowed to evaluate the microcirculation (local circulation) in the area of research. Physical examination was carried out by means of "Wosteo" product. On the foundation of received photoplethyzmogram (the high-amplitude pulsatile (Fig. 1a), the low-amplitude pulsatile (Fig. 1b), nonpulsatile (Fig. 1c)it was determined the nature of blood flow. Based on these data the sensitivity, specificity, and predictive LPPH value in diagnostics of lower limb arteries' occlusion diseases were calculated. Sensitivity was defined as a sign of positive sign of the research conducted among the sick people, specificity - a negative sign among healthy ones, predictive value - as the probability of the disease presence (absence), knowing the results of the analysis ${ }^{8}$.

Optical Fibers and Their Applications 2015, edited by Ryszard S. Romaniuk,

Waldemar Wojcik, Proc. of SPIE Vol. 9816, 98161K · (c) 2015 SPIE

CCC code: $0277-786 \mathrm{X} / 15 / \$ 18 \cdot$ doi: $10.1117 / 12.2229042$

Proc. of SPIE Vol. $981698161 \mathrm{~K}-1$ 


\section{SUBSEQUENT RECOGNITION}

Having examined the key group, the pulse was determined on all the levels of the lower limbs, the foot skin was warm, pale pink with fast red dermographism $(8-26 \mathrm{sec})$. Manteuffel and Laignel-Lavastin's test did not exceed 4 sec. The reactive wrist hyperemia occurred for $8.2 \mathrm{sec}$ at a pressure of $100-140 \mathrm{~mm} \mathrm{Hg}$. The foot reactive hyperemia occurred for 4-14 sec, at a pressure of 100-160 $\mathrm{mm} \mathrm{Hg}$. The high-amplitude (28 people) and low-amplitude (1 person) pulsing blood flow was registered by LPPH. 13 patients noted the chilliness of foot, paresthesia, hypothermia of foot skin in the II stage of ischemia. They had pale skin, slow red $(30-48 \mathrm{sec})$ dermographism, predisposition to hypertension. The Manteuffel and Laignel-Lavastin's test was $2.6 \mathrm{sec}$. Walking distance equaled 140-240 $\mathrm{m}$. The wrist reactive hyperemia occurred for 4-10 sec at a pressure of 110-170 $\mathrm{mm} \mathrm{Hg}$. The reactive foot hyperemia occurred for 17-73 sec, at a pressure of 70-120 mm Hg. The ratio of the blood saturation index on the foot to the analogous index on the wrist was - 0,93 \pm 0,04 . Having been examined by LPPH, it turned out that 12 patients had high-amplitude pulsatile blood flow and 6 - the low-amplitude pulsatile blood flow.

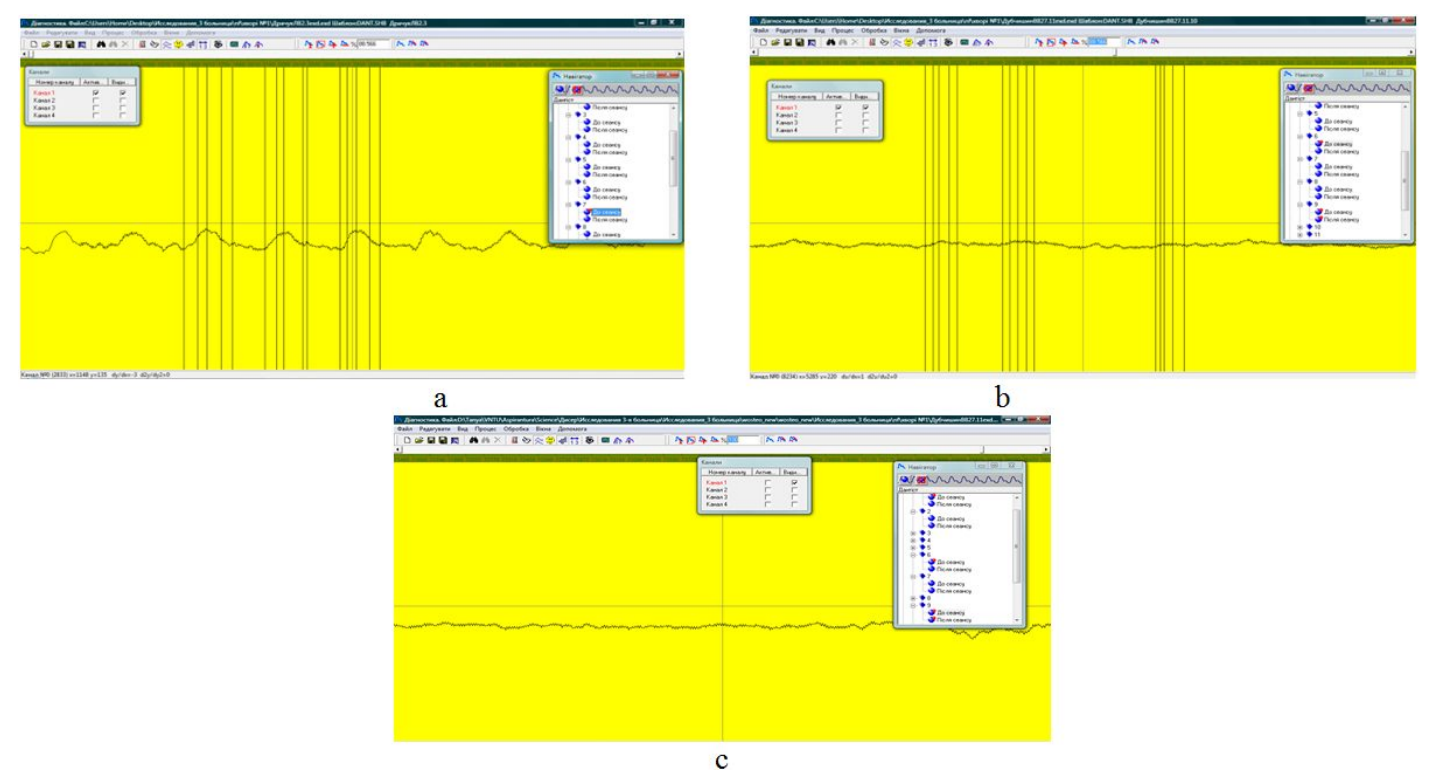

Figure 1. Determining the flow of blood: a) high-amplitude pulsatile, b) low-amplitude pulsatile;

c) nonpulsatile

Patients with stage IIIA ischemia always felt cold and paresthesia in the foot and pain when they rest - this forced one to lower leg 1-3 times a night. The foot's skin was cold and pale with a white dermographism. The Manteuffel and LaignelLavastin's test was 6-10 sec. Walking distance equaled 25-50 .The reactive wrist hyperemia occurred at 4-12 sec at a pressure of 110-170 mm Hg, on foot - for 62-98 sec at SP below $60 \mathrm{~mm} \mathrm{Hg}$. There were recorded 5 patients with a lowamplitude pulsatile blood flow and 3 - with nonpulsatile after LPPH. Patients with ischemia III $b$ degree suffered from swelling in foot. They complained of the constant feeling of cold in the foot and pain at rest, that forced them to lower a leg 4-8 times a night. The foot's leather was cool and purple with a long (over $50 \mathrm{sec}$.) white dermographism. The Manteuffel and Laignel-Lavastin's test was 7-11 sec. Walking distance did not exceed $30 \mathrm{~m}$. The reactive wrist hyperemia occurred for $4.12 \mathrm{sec}$. at SP 100-180 mm Hg, on foot - for 79-109 sec at SP below $50 \mathrm{~mm} \mathrm{Hg}$. There were recorded 2 patients with a low-amplitude pulsatile blood flow and 10 - with nonpulsatile after LPPH . Patients with ischemia of the IV degree complained of the feet coldness, paresthesias, constant, mostly nocturnal pain in the foot that forced to lower the leg 4-12 times per night. The skin of feet was cold, pale-bluish or purple, marble with a white dermographism. All the patients had swelling on their foot and shin, necrotic changes of toes and fingers. The Manteuffel and Laignel-Lavastin's toes test was 9-19 sec. The reactive wrist hyperemia occurred for 4-12 sec, with SP below 100-170 mm Hg. The reactive hyperemia occurred for 2-5 min, in the shin area - for 77-129 sec., in the knee area - for 38-69 sec. at SP below $50 \mathrm{~mm} \mathrm{Hg}$. After LPPH blood flow of foot was defined as nonpulsatile, and one of shin as throbbing with a low amplitude. All the patients were registered with a nonpulsatile blood flow after LPPH. Based on these data it was calculated sensitivity and specificity of LPPH in diagnostics of occlusive diseases spreading in lower 
limbs' arteries. Out of 29 individuals, who had not had any symptom of lower limb arteries' obliterating diseases , 28 had a high-pulsatile blood flow, and in only one case the low throbbing blood flow.

In the presence of ischemia, the high-amplitude pulsatile blood flow was registered in 12 patients (none with critical ischemia), with the low amplitude - in 13 patients (with critical ischemia - 7), with nonpulsatile - in 27 (with critical ischemia - 27).

Consequently, diagnosing ischemia we could see that the specificity of pulsatile blood flow was $100 \%$, of highamplitude pulsatile one was $96.6 \%$. It was also $100 \%$ and $67 \%$ relatively while critical ischemia. The sensitivity of blood flow pulsatility index in ischemia terms was $52.8 \%$, of a high-amplitude pulsatile index reached $77.4 \% .80 \%$ and $100 \%$ relatively while critical ischemia. Prognostic value of pulsatile blood flow index in the diagnostics of ischemia was $100 \%$ in presence of $-46.3 \%$, of high-amplitude relatively $97.6 \%$ and $30 \%$. While critical ischemia predictive value was $100 \%$ without pulsatility of blood flow, in the presence of $-28 \%$, with high-amplitude relatively $85.4 \%$ and $0 \%$.

\section{DISCUSSION OF RESULTS}

In general physical data reflects the state of regional hemodynamics adequately. However, hypo- or hyperesthesia was often observed when diabetic neuropathy. The patches of necrosis while maintaining a foot pulse have been noticed. Walking distance might be shortened if the pathology of the musculoskeletal system was found. A test on dermographism is too much subjective, in particular, it depends on the stamping strength. It is uncomfortable to evaluate the results of Manteuffel and Laignel-Lavastine tests if somebody has a purple, pale or pale bluish skin. In the latter case you should pay attention to the turgor tissues and the quickness of hole extinction. Nevertheless, there is too much subjectivity in the last words. Physical examination does not allow us to carry out a proper evaluation of collateral circulation.

Reactive hyperemia is a sensitive test. Endothelium synthesizes vasodilators, anhioprotektors, (nitric oxide, etc.) vasoconstrictors, prothrombotic factors (thromboxane A et al.) and plays an important role in regulating vascular reaction and hydraulic arteries' resistance, free radical oxidation, intravascular thrombosis, inflammatory and autoimmune reactions ${ }^{8,11}$. Endothelial are sensitive to the speed of blood flow. The blood flow velocity is much greater than on the initial level while reactive hyperemia. Hence, the production of nitric oxide is increasing ${ }^{10-11}$. Positive changes in the indices have been registered among the patients with the preserved collateral circulation. Perfusion hyperemia value increases by $150-250 \%$. Patients who have arterial occlusion on the basis of endothelial disfunction suffer from interval rasing till flushing. Interval duration equals the quantity of blocks and depends on the seriousnees of ishemia. The smaller the maximum significance of perfusion and degree of increase relatively to the initial level is, the more difficult decompensation of regional circulation is .

There is a spasm of arterioles and precapillary sphincters and increase peripheral resistance with the ischemia the II degree. With ischemia of the III-IV degree atony of vessels occurs (until paresis), including arteriolovenular shunts, deep microcirculation disturbances and irreversible tissue changes ${ }^{4,5,9}$. With critical ischemia the initial level of blood flow was high, but not pulsatile, that demonstrates the violation of myogenic tone and paresis of capillary sphincters in patients with diabetic angiopathy combined with atherosclerosis ${ }^{7}$.

Table 1a. Dependence foot-hand coefficient on the degree of ischemia.

\begin{tabular}{|l|c|c|c|c|c|}
\hline Degree of ischemia & $\begin{array}{c}\text { The number of } \\
\text { examined } \\
\text { lower } \\
\text { extremities }\end{array}$ & $\begin{array}{c}\text { The number of } \\
\text { examined } \\
\text { patients }\end{array}$ & $\begin{array}{c}\text { Foot-hand } \\
\text { coefficient, \% }\end{array}$ & Interval & $\begin{array}{c}\text { Need the individual } \\
\text { examination }\end{array}$ \\
\hline Healthy & 24 & 17 & $78,4 \pm 3,7$ & $\begin{array}{c}44,4- \\
125,8\end{array}$ & $40,1-$ \\
\hline Subcompensated (SC) & 25 & 21 & $29,4 \pm 2,3$ & $13,8-69,1$ & $22,0-36,0$ \\
\hline Decompensated (DC) & 37 & 30 & $15,3 \pm 2,2$ & $0,3-49,4$ & $9,0-21,0$ \\
\hline
\end{tabular}

Much worse performances of the test there are on the foot with critical ischemia than in the knee area due to a good collateral development in the thigh area, hip and knee. Development of collaterals below this level is much worse. This method allows to evaluate the adequacy of collateral circulation at a certain level, which is important in determining the 
level of preservation of limbs. LPPH is useful for objectification results. The level of ST is Informative test, which appears reactive hyperemia. This reflects the volumetric rate of flow of blood through collaterals. The results satisfactorily correlate with the severity of ischemia and as collateral circulation. Informative test with reactive hyperemia is over $80 \%$.

For a more convenient and reliable comparison of experimental results all patients were divided into 3 groups: 1 without occlusion of arteries, 2 - decompensated or critical ischemia (III and IV stages of ischemia), 3 - subcompensated ischemia (II stage of ischemia). Research results are shown in the tables $1 \mathrm{a}, \mathrm{b}$ and 2.

Table $1 \mathrm{~b}$. The degree of ischemia at a certain interval of the foot-hand coefficient determining.

\begin{tabular}{|l|c|c|c|}
\hline \multirow{2}{*}{ Foot-hand coefficient, \% } & \multirow{2}{*}{ Healthy } & \multicolumn{2}{|c|}{ Degree of ischemia } \\
\cline { 3 - 4 } & & $\begin{array}{c}\text { Subcompensated } \\
\text { (SC) }\end{array}$ & $\begin{array}{c}\text { Decompensated } \\
\text { (DC) }\end{array}$ \\
\hline & & \multicolumn{3}{|c|}{ The number of examined patients } \\
\hline $0-20,0$ & 0 & $6(25 \%)$ & $27(73 \%)$ \\
\hline $20,1-40,0$ & 0 & $15(63 \%)$ & $9(24,3 \%)$ \\
\hline $40,1-70,0$ & $12(50 \%)$ & $3(12,5 \%)$ & $1(2,7 \%)$ \\
\hline $70,1-130,0$ & $12(50 \%)$ & 0 & 0 \\
\hline $\begin{array}{l}\text { The number of examined lower } \\
\text { extremities }\end{array}$ & 24 & 24 & 37 \\
\hline $\begin{array}{l}\text { The average of foot-hand coefficient, } \% \\
\text { nyyy }\end{array}$ & $78,4 \pm 3,7$ & $29,4 \pm 2,3$ & $15,3 \pm 2,2$ \\
\hline
\end{tabular}

Table 2. Research results.

\begin{tabular}{|c|c|c|}
\hline \multirow{2}{*}{ Foot-hand coefficient, \% } & Decompensated (DC) & \multirow{2}{*}{ Research results } \\
\cline { 2 - 3 } & $\begin{array}{c}\text { The average of foot-hand } \\
\text { coefficient } 15,3 \pm 2,2 \%\end{array}$ & 6 amputations \\
\hline $0-20,0$ & 27 patients & 1 amputation \\
\hline $20,1-40,0$ & 9 patients & lower extremity was saved \\
\hline $40,1-70,0$ & 1 patients & \\
\hline
\end{tabular}

The graphical dependence of foot-hand coefficient on the degree of ischemia is shown in Fig. 2.

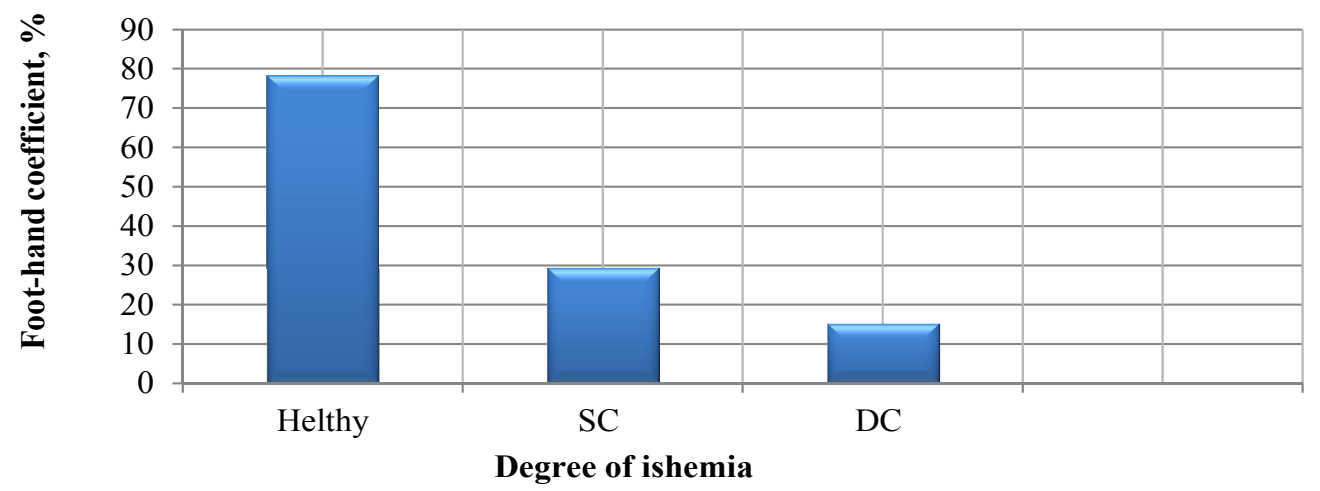

Figure 2. Dependence of foot-hand coefficient on the degree of ischemia. 


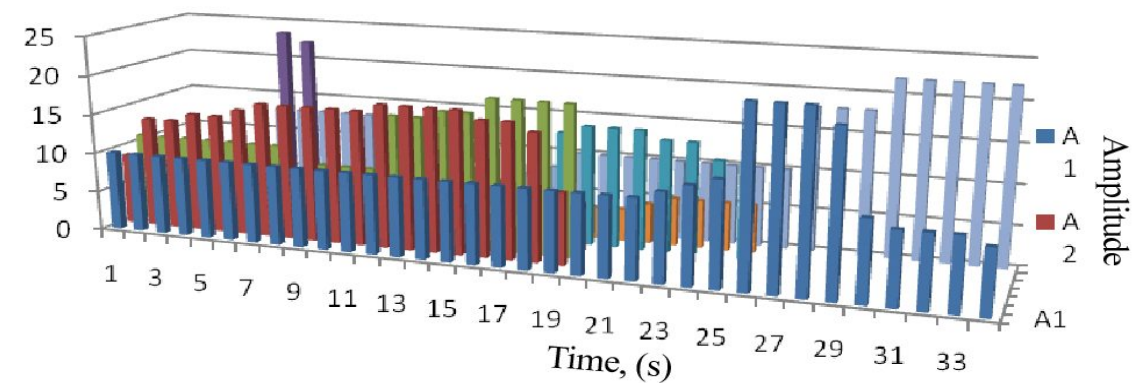

a)

Decompensated ischemia

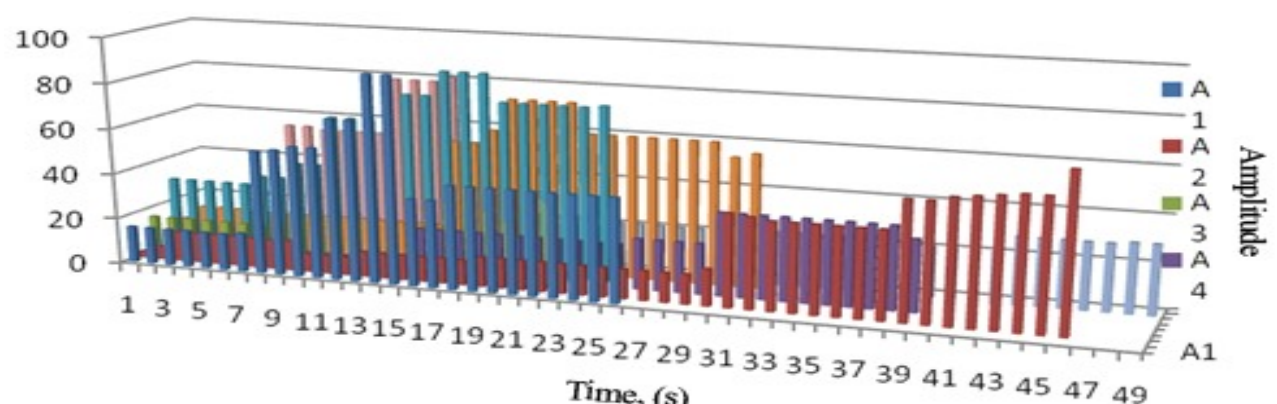

b)

Subcompensated ischemia

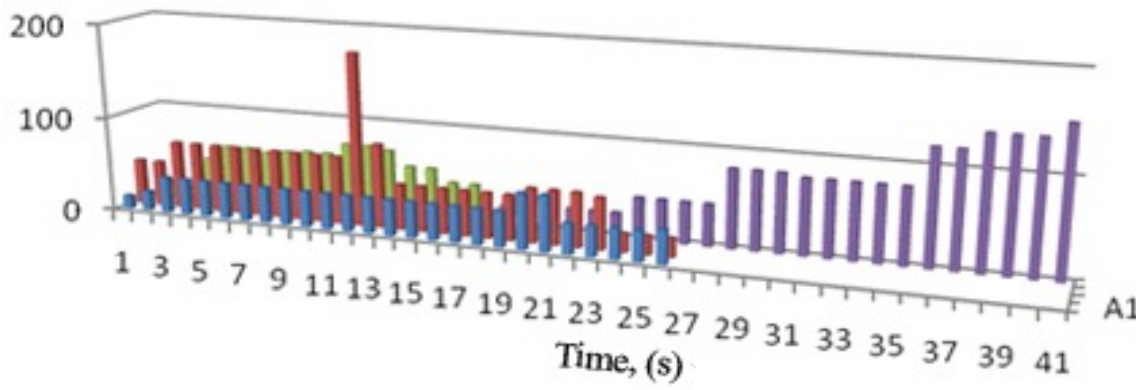

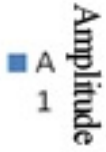

c)

Subcompensated +

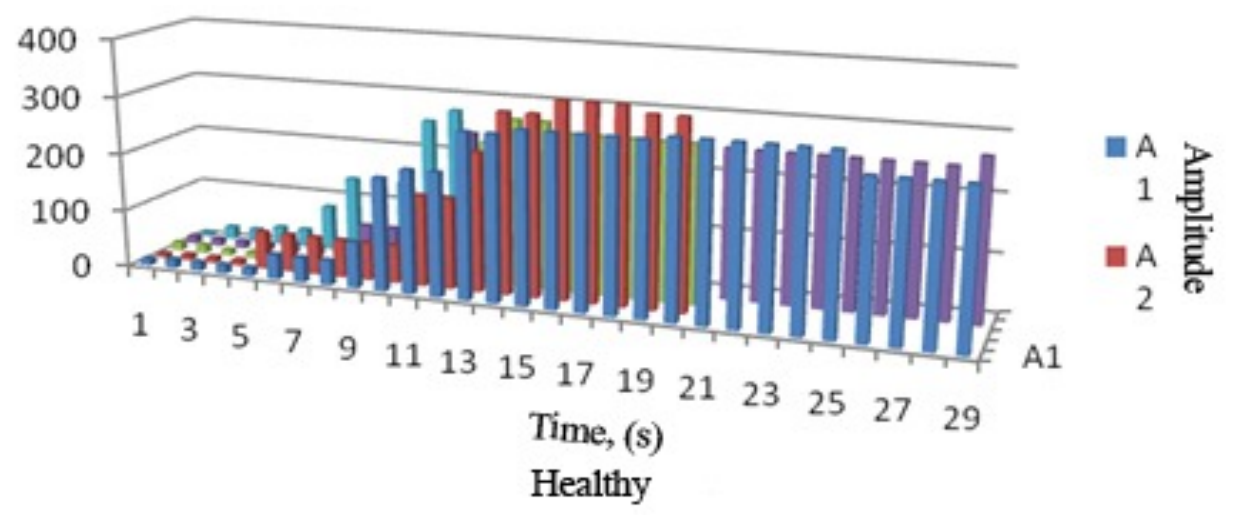

Figure 3. Changing of the blood flow amplitude, depending on the degree of ischemia: a) decompensated ischemia; b) subcompensated ischemia; c) subcompensated +; d) healthy. 
Dynamics of amplitude increased of blood flow after the test for reactive hyperemia is shown in Fig. 3 (a - d). The amplitude change for 7 patients with decompensated ischemia are shown in Fig. 3a. 8 patients with subcompensated ischemia are represented in Fig. $3 \mathrm{~b}$., the amplitudes of 4 patients were grouped into a separate group with ischemia subcompensated + (thay have seen increasing of the blood flow amplitude) are shown in Fig. 3c.

\section{CONCLUSION}

As a result of experimental and clinical studies 7 amputations were made, 1 lower extremity was saved. Other patients were assigned to individual treatment and medical supervision. So, LPPH method allows to determined pulsatility of blood flow in different areas of the foot and lower leg, the degree of compensation and conservation perspectives limb and of amputation level. The informativity of method is more than $90 \%$. LPPH is the highly informative method to evaluation the pulsatility of blood flow in a specific area. The high pulsatile blood flow is the most informative parameter.

\section{REFERENCES}

[1] Lazarek, J., "Image analysis methods - analysis of mammographic image based on textural features," IAPGOS 3(4), $10-13(2013)$.

[2] Borys, M., "Eye-tracking in diagnosis of neurodegenerative disease," IAPGOS 5(2), 55-63 (2015).

[3] Petruk, V. G. and Kolisnik, P. F., [UNIVERSUM- Vinnytsia], Photoplethysmographic technologies of the cardiovascular system control, 254 (2007).

[4] Guch, A. A. "Factors of development of of arterial long-lasting insufficiency in defeat abdominal of aorta and the part of periferal arteries," Surgery of Ukraine 2, 74-75 (2002).

[5] Guch, A. A, Klimenko, I. T, Vlaykov, G. G and Shuvalova, I. N., "Changes of regional hemodynamics and microcirculation in the tissues lower extremities in patients with obliterating atherosclerosis in I-II stages," Clean Surgery 6, 25-27 (2003).

[6] Mishalov, V. G., Boychak, M. P., Chernyak, V. A., Gladka, A. Yu., Selyuk, V. M. amd Koval, B. M., "Diagnosis and treatment of chronic critical ischemia of the lower limbs, combined with multifocal atherosclerosis". Method recommendations, 62, (2007).

[7] Kazakov, Yu. I. and Bobkov, B. B., "Study of microcirculation in patients obliterating Disease of arteries of lower extremities," Methodology of flowmetry, 55-62 (1997).

[8] Altman, D. G. and Bland, J. M. "Statistics Notes: Diagnostic tests 1: sensitivity and specificity," BMJ 308, 1552 (1994).

[9] Celermajer, D. S., Sorensen, K. E., Gooch, V. M., et al., "Non-invasive detection of endothelial dysfunction in children and adults at risk of atherosclerosis," Lancet 340, 1111-1115 (1992).

[10] Cooke, J. P., Rossitch, E. and Andon, N., "Flow activates endothelial potassium channel to release endogenous nitrovasodilator," Clin Invest. 88, 1663-1671 (1991).

[11] Vane, J. R., Anggard, E. E. and Botting, R. M., "Regulatory functions of the vascular endothelium," New Engl. J. Med. 323, 27-36 (1990). 